\title{
Characteristics of smallholders' goat production systems and effect of Boer crossbreeding on body measurements of goats in Burundi
}

\author{
Josiane Manirakiza ${ }^{1 *} \mathbb{D}$, Gilbert Hatungumukama ${ }^{1}$, Badi Besbes ${ }^{2}$ and Johann Detilleux ${ }^{3}$
}

\begin{abstract}
As part of a national action plan to manage animal genetic resources in Burundi, we characterized smallholders' goat production systems and assessed the effect of Boer crossbreeding on animal body measures. To that end, 319 farmers were surveyed in the five agro-ecological zones of Burundi and the zootechnical measures of 939 adult goats were taken. Cluster analysis of the goat production systems resulted into two opposed groups and one intermediate. On the one hand, there are the dry lowlands systems characterized by large herds composed mainly of indigenous animals grazing freely, and having high market characteristics. On the other hand, there are the humid highlands systems characterized by small herds composed of indigenous and crossbred animals in stall feeding or herding/tethering systems, and by low market characteristics. Fixed effect linear models were used to evaluate the effect of Boer crossbreeding on body weights and linear body measures, after adjustment for age, sex, grazing systems and agro-ecological zones. Results showed that least square means for body weights of adult Boer crossbreds were $4.74 \mathrm{~kg}$ higher than those of indigenous goats, which was lower than expected. Least square means for linear body measures of Boer crossbreds were significantly higher than those of indigenous breeds: differences in chest girth, body length and height at withers were $4.88 \mathrm{~cm}, 5.59 \mathrm{~cm}$ and $4.82 \mathrm{~cm}$, respectively. Goats were heavier and greater in linear measures in lowlands than in highlands. The advantages and issues of a selection programme within indigenous breeds are discussed as an alternative to the crossbreeding programme.
\end{abstract}

Keywords: Goat genetic resources, Production systems, Agro-ecological zones, Multivariate analysis, Body measures, Least square means, Burundi

\section{Introduction}

Goat farming is one of the largest agricultural sectors in developing countries, and about $35 \%$ of the world goat population (heads) is found in Africa (Skapetas and Bampidis 2016). In Burundi, the number of goats is high, with an estimate of 3.2 million heads, against 3.4 million for poultry, 1.1 for cattle, 0.8 for pig and 0.5 for sheep (MINEAGRIE 2017). It is also expected this number will increase because it tends to follow the growth of human population. Indeed, in the 50 least developed countries, the annual growth rates of goat and human populations

\footnotetext{
* Correspondence: josianeman@yahoo.fr

1 Department of Animal Health and Productions, Faculty of Agriculture and Bio-Engineering, University of Burundi, BP 2940 Bujumbura, Burundi Full list of author information is available at the end of the article
}

are $2.6 \%$ and $2.4 \%$, respectively (Devendra 2010). The reasons for this increase are multiple. An important reason is that goats necessitate a lower initial investment and are easier to sell compared to larger animals. As such, poor smallholders often considered them as a means to be financially secure (Kosgey et al. 2006; Peacock 2005). Additionally, feed efficiency of goats is higher than that of other ruminants, so they are best suited to small-scale farms (Darcan and Silanikove 2018). Finally, indigenous goats are perceived as more resilient to climate changes than other ruminant species (Pragna et al. 2018). Despite these advantages, goat production in smallholding systems continue to face many issues among, including the fact that policy-makers are often more interested to develop enhanced breeding of 
large ruminants to the detriment of that of goats (Mueller et al. 2015). Subsequently, goat production remains extensive and productivity levels are low (Devendra 2010).

It would be possible to increase goats' productivity by implementing a genetic improvement programme, as is done in many countries. To plan such programme, a good understanding of breed characteristics under their production systems is required (FAO 2012). According to Otte and Chilonda (2002), livestock production systems may be classified according to different criteria, including the agro-ecological zone (AEZ), farming systems and breeds of animals kept.

\section{Study area}

In this respect, Burundi is divided into five AEZ (Bidou et al. 1991), fitting into two groups. On the one hand, the dry lowlands of western Imbo (IMB), the western escarpment of Mumirwa (MUM) and the depressions of the northeast (DNE) are characterized by dry seasons varying between 5 and 6 months a year, at 800 to 1150 $\mathrm{m}$ of altitude, with 800 to $1200 \mathrm{~mm}$ of annual rainfall and mean temperatures of $24{ }^{\circ} \mathrm{C}$ or above. On the other hand, there are the humid highlands of Congo-Nil-Crest $(\mathrm{CNC})$ and the Central Highlands (CHL). In these zones, dry seasons vary between 3 and 4 months a year, at 1400 to $2500 \mathrm{~m}$ of altitude, 1500 to 2000 of rainfall and temperatures between 10 and $20^{\circ} \mathrm{C}$. In terms of demography, $\mathrm{CHL}$ has the highest human population pressure (more than 300 inhabitants $/ \mathrm{km}^{2}$ ) while the other zones are relatively less populated (less than 300 inhabitants/ $\mathrm{km}^{2}$ ) (Ministère de l' Intérieur 2010).

\section{Farming systems}

Burundians practice two main farming systems: the very common traditional extensive system (TES) in which goats are either tethered or herded according to the availability of pastures and secondly the mixed croplivestock system (MCLS). In the latter, animals are mainly stall-fed with forage crops and crop residues. The latter practice became common as a response to the degradation of lands caused by soil erosion (steep slopes) and unsuitable land use (Jeníček and Grofová 2015). The MCLS allows the production of high quantities of manure used for crop fertilization and also decreases soil erosion thanks to grass hedgerows planted along the level curves. At the global level, MCLS has been recognized as playing a major role in the livelihoods of smallholders; it provides them significant quantities of both livestock and crop food products (Tarawali et al. 2011).

\section{Livestock}

Concerning the breed, the Burundian goat is typical of the Small Eastern African breed. It is a small, very hardy and mostly black animal although grey or black-grey animals can be found (Wilson 1991). It is reputed to be a poorer meat producer than some exotic meat breeds such as the Boer goats. Therefore, Boer goat bucks have been used in many countries to crossbreed with indigenous does, and their offspring are more efficient red meat producers (Erasmus 2000; Malan 2000). This motivated the Government of Burundi to import Boer bucks from Tanzania and Uganda since 2005, with the consequence that the goat population in Burundi is presently a mixture of indigenous goats and Boer crossbreds in unrecognized proportions (MINEAGRIE 2010). However, it is not known whether Boer crossbreds are competitive compared with the indigenous breed in the Burundi environment.

Therefore, this study attempts (i) to provide a good understanding of the goat production systems in terms of management, farmers' motives and market characteristics in the five AEZ and (ii) to evaluate the impact of Boer crossbreeding on body measures.

\section{Materials and methods Data collection}

Data consisted of answers to a questionnaire to farmers and of measures on animals. The questionnaire covered four main topics: (a) general household characteristics, (b) characteristics of the farming system, (c) main purpose for raising goats and (d) market characteristics. It was administered to 319 farmers from November 5, 2014, to January 6, 2015 (short rainy season). Surveyed farmers were from all five AEZ: 41 were located in IMB, 51 in MUM, 56 in CNC, 108 in CHL and 63 in DNE. We used the purposive sampling technique to select representative farmers having the goat breed type and of livestock system in each AEZ. During each visit, an enumerator interviewed the farmers using a questionnaire while two others took measurements on body weight and linear measures of animals of more than 1 year of age.

We characterized the phenotype of 939 adult goats. Animals were categorized as either indigenous or crossbred according to the farmers' declarations and our visual observations of the goat's physical characteristics such as the presence of dropped ears and conformation (Campbell 2003). Body measures (BW = body weight, $\mathrm{BL}=$ body length, $\mathrm{CG}=$ chest girth, $\mathrm{HW}=$ height at withers) were taken with a mobile weighting scale and a measuring tape. Four age clusters were made based on goat dentitions (FAO 2012): 1 to 2 years, 2 to 3 years, 3 to 4 years and 4 years or more. Herds were categorized into two management groups: pure indigenous herd and mixed herd of indigenous and crossbreds.

\section{Data analysis}

All analyses were performed with R software: Rx64 3.3.1 


\section{Descriptive statistics}

We computed the percentages of respondents that gave a particular answer as the proportion of the number of people that answer the question. For the quantitative variables, we computed the means and standard deviations.

\section{Typology of goat production systems}

To establish a typology of the herds, we selected nine items from the questionnaire that address important herd characteristics and conducted a multiple correspondence analysis (MCA) followed by hierarchical classification analysis (FactoMineR package) (Lê et al. 2008; Husson et al. 2010). Variables included in the analyses are described in Table 1. Multiple correspondence

Table 1 Variables used in the multivariate analysis of the goats' production systems

\begin{tabular}{|c|c|}
\hline Variables & Categories \\
\hline \multirow[t]{3}{*}{ Grazing modes } & Free grazing \\
\hline & Herding and tethering \\
\hline & Mixed crop-livestock system \\
\hline \multirow[t]{3}{*}{ Type of grazing area } & Communal pastures \\
\hline & Individual pastures \\
\hline & Stall feeding \\
\hline \multirow[t]{2}{*}{ Presence of litter in the stall } & Yes \\
\hline & No \\
\hline \multirow[t]{2}{*}{ Use of forage crops in the feed } & Yes \\
\hline & No \\
\hline \multirow[t]{3}{*}{ First purpose for keeping goats } & Manure \\
\hline & Sale \\
\hline & Both \\
\hline \multirow[t]{3}{*}{ Size of flock } & Small: less than 5 goats \\
\hline & Medium: from 5 to 10 goats \\
\hline & Large: over 10 goats \\
\hline \multirow{3}{*}{$\begin{array}{l}\text { Level of income from goats' sale } \\
\text { (in the year before the survey) }\end{array}$} & Low: less than $50,000 \mathrm{BIF}$ \\
\hline & Medium: from 50,000 to $100,000 \mathrm{BIF}$ \\
\hline & High: more than $100,000 \mathrm{BIF}$ \\
\hline \multirow[t]{2}{*}{ Breed types } & $\begin{array}{l}\text { Flock with only pure indigenous } \\
\text { goats }\end{array}$ \\
\hline & $\begin{array}{l}\text { Flock with indigenous goats and } \\
\text { Boer crossbreds }\end{array}$ \\
\hline \multirow{3}{*}{$\begin{array}{l}\text { Money spent on veterinary care } \\
\text { (in the year before the survey) }\end{array}$} & Low: less than 5000 BIF \\
\hline & Medium: from 5000 to $10,000 \mathrm{BIF}$ \\
\hline & High: more than $10,000 \mathrm{BIF}$ \\
\hline \multirow[t]{5}{*}{ Agro-ecological zone } & Congo-Nil-Crest \\
\hline & Central highlands \\
\hline & Imbo \\
\hline & Mumirwa \\
\hline & Depressions of the Northeast \\
\hline
\end{tabular}

BIF Burundian francs (1 USD $=1553.05$ in December 2014) analysis is a method used to summarize a set of categorical variables into a small number of dimensions. We used these dimensions in the hierarchical classification analysis to group respondents according to the cluster to which they belong to. AEZ was used as an illustrative variable; it did not actively affect the construction of dimensions but projected on them to ease the interpretation of the generated clusters. Finally, we used chi-square and exact Fisher's tests to assess if AEZ, socio-economic characteristics of households (i.e. age range, level of education and household's size), characteristics of purchasers of goats from sampled farmers and the required time to reach the animal market were significantly different among these clusters. For all analyses, $p$ values were set at $1 \%$. Graphical displays present the proximities between the subjects and show the associations between the categorical variables.

\section{Animal performances}

We used fixed effects linear models to determine whether age, sex, grazing system and other management characteristics influence BW, BL, HW and CG of an animal. The equation for the model is:

$$
\begin{aligned}
\mathrm{Y}_{\mathrm{ijklmnp}}= & \mu+\mathrm{A}_{\mathrm{i}}+\mathrm{S}_{\mathrm{j}}+\mathrm{AS}_{\mathrm{ij}}+\mathrm{G}_{\mathrm{k}}+\mathrm{T}_{1}+\mathrm{TG}_{\mathrm{tl}}+\mathrm{M}_{\mathrm{m}} \\
& +\mathrm{Z}_{\mathrm{n}}+\mathrm{MZ}_{\mathrm{mn}}+\mathrm{F}(\mathrm{MZ})_{\mathrm{omn}}+\mathrm{e}_{\mathrm{ijklmnp}}
\end{aligned}
$$

where $Y_{i j k l m n p}$ is the BW, CG, BL or HW of the $p$ th animal of the $i$ th age group, $j$ th sex and $k$ th breed type raised in the $l$ th herd type, $m$ th grazing mode and $n$th agro-ecological zone; $\mu$ is the overall mean; $A$ is the age group $(i=1,2,3,4), S$ is for the sex of the animal $(j=1$, $2) ; G$ is the breed type $(k=1,2) ; T$ is the type of herd $(l=1,2) ; M$ is the mode of grazing $(m=1,2,3) ; Z$ is the agro-ecological zone $(n=1,2,3,4,5)$; and $F$ is the farm $(o=1,2, \ldots, 313)$. Residuals $\left(e_{i j k l m n p}\right)$ are assumed independently and identically normally distributed with null mean and variance $\sigma^{2}$. Computations were performed with the procedures GLM and UNIVARIATE of SAS (v9.3). Significant thresholds were set at $p=0.05$.

\section{Results}

\section{Descriptive characteristics of herds and animals}

The main source of income in most farms surveyed (84.4\%) came from agricultural products while 15.6\% had other off-farm activities. Farmers' level of education was generally low with $57.4 \%$ not going beyond primary school, $21.6 \%$ followed informal schooling (trained in reading and writing), $13.8 \%$ had no schooling at all and therefore were illiterate and $7.2 \%$ had reached secondary school. Almost half of the sample farmers (51.6\%) were between 30 and 50 years old, $24.8 \%$ between 50 and 60 years old, $15.7 \%$ over 60 years old and $7.9 \%$ less than 30 
years old. Most of them (85.3\%) were men while others were widowed women.

The first goal in keeping goats was either selling them $(24.3 \%)$, both selling them and producing manure $(47.6 \%)$, or producing manure exclusively $(28.1 \%)$. Most of the goats' keepers (69.9\%) used litter to increase the quantity of manure for crop fertilization. About $60 \%$ of them had sold their goats the year prior to the survey. Sale purposes were mostly to answer regular or emergency needs $(74.1 \%)$, to buy a cow (11.6\%), to dispose of animals with health issues (10.9\%) and to purchase a plot of land (3.4\%). The level of income from the sales was low, with an average of 91,917 BIF (range 10,000$595,200 \mathrm{BIF}$; or an equivalent of 59.2 USD (range 6.4 383.2 USD), with a rate of 1553.05 BIF for 1 USD in December 2014.

Feedstuffs included either pastures or forage crops supplemented with crop by-products, and no concentrates were used. Around $46.8 \%$ of the interviewed people indicated that their forage was insufficient to cover the needs of their animals throughout the year, especially in the dry season. Goats were kept in the family home or in the kitchen (64.9\%) to avoid thefts at night, and only $35.1 \%$ kept them within homestead enclosure.

Gastrointestinal parasitaemia was the most important pathology (56.5\%), followed by pneumonia (12.4\%) and tick-borne diseases (12.2\%). The mortality rate for kids under 1 year was estimated at $27.2 \%$ for herds of indigenous and crossbred goats and at $18.3 \%$ for herds of indigenous goats exclusively. The household's low income to pay veterinary drugs was the main reason $(87.3 \%)$ for explaining mortality rates. Indeed, the level of expenditure on veterinary treatment was very low, with an average of 5919 BIF (range 200-48,000 BIF), or an equivalent of 3.8 USD (range 0.1 - 30.9 USD) with a rate change of 1 USD = 1553.05 BIF in December 2014 .

The mean ( \pm standard deviation) number of goats per farm was $6.6 \pm 4.8$. The largest herds $(10.8 \pm 6.4)$ were found in IMB and the smallest ones $(5.4 \pm 2.7)$ in CNC and CHL. Usually, goats were not the only species kept: $64.2 \%$ of the farmers owned also chickens $(n=7.5 \pm 6.5)$, $31.3 \%$ owned pigs $(n=1.4 \pm 1)$ and $28.8 \%$ owned cows $(n=1.9 \pm 1)$. Indigenous breed represented $69.3 \%$ of the all goats in the flocks visited. However, Boer crossbreds were better appreciated than local goats by $54.4 \%$ of the respondents because of their good body conformation and higher market prices ( $71.5 \%$ of the respondents) and high growth rate $(28.5 \%$ of the respondents). On the other hand, $36.6 \%$ of the respondents preferred indigenous goats because of their high resistance to diseases (69.5\%), low feed requirements (19.6\%) and high fertility $(10.9 \%)$. Note that $9 \%$ of the respondents had no preference on the breed type. The proportion of male goats in the herds were $37.7 \%$ for kids less than 1 year of age,
$10.5 \%$ for kids between 1 and 2 years of age and $0 \%$ afterwards. Only $15.3 \%$ of the respondents owned bucks; those who did not have had to borrow or to rent one if needed. The age for selling bucks was $5.9 \pm 1.9$ months. The age at sale of females was $6 \pm 1$ years $(5.1 \pm 2$ parity number). The goat's weight was of $23.1 \pm 4.7 \mathrm{~kg}$ on average (range 15 to $40 \mathrm{~kg}$ ). The BW, CG, BL and HW of indigenous breed were $22.3 \pm 4.1 \mathrm{~kg}, 67.1 \pm 5.6 \mathrm{~cm}$, $59.0 \pm 5.7 \mathrm{~cm}$ and $54.2 \pm 4.8 \mathrm{~cm}$, respectively, while these were $26.1 \pm 5.4 \mathrm{~kg}, \quad 71.9 \pm 6.1 \mathrm{~cm}, \quad 64.2 \pm 6.1 \mathrm{~cm}$ and $58.9 \pm 5.2 \mathrm{~cm}$ for Boer crossbreds.

\section{Typology of goat production systems}

The amount of variation explained by each dimension of the MCA (inertia) is given in Fig. 1. From this, we retained only the first three dimensions $(39.76 \%$ of the total variance) because each additional dimension contributed little to the total variance.

Figure 2 shows the distribution of herds according to the first (19.34\% of the total variance) and second (11.53\% of the total variance) dimensions. The first dimension distinguished two types of herds. On the right of Fig. 2, there are large herds where goats graze freely in communal pastures; farmers have a market-driven objective for breeding them (positive values). On the left, there are small herds kept in MCLS in which goats are stall-fed with forage crops; the objective for breeding the goats is to produce manure (negative values). The second dimension discriminated two reverse situations (Fig. 2 top) from an intermediate one (Fig. 2 bottom ). On the one hand, there are herds in MCLS in which goats are stall-fed with forage crops, and on the other hand, herds are kept for selling and generate high income (positive values). The intermediate situation is constituted of herds kept under the herding/tethering mode in which goats graze either in communal or individual pastures and that generate medium income (negative values). Figure 3 shows the distribution of herds

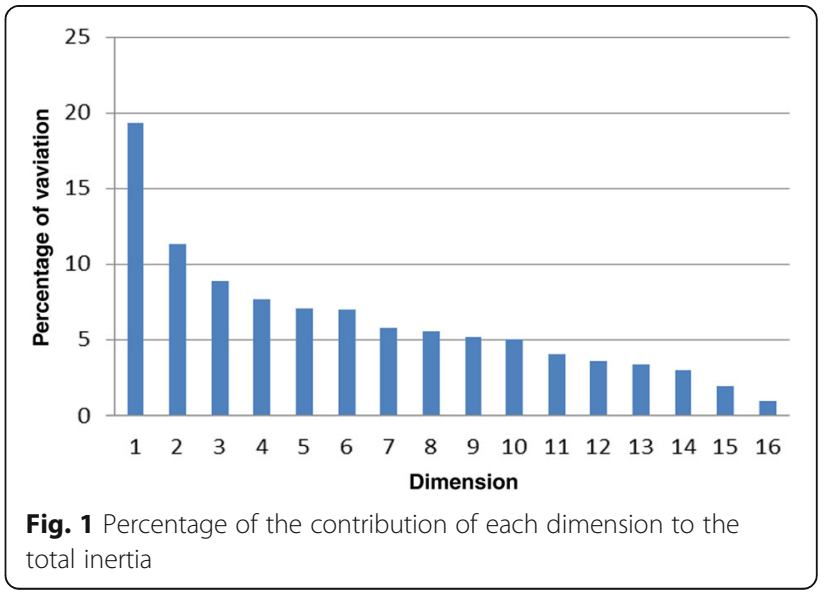




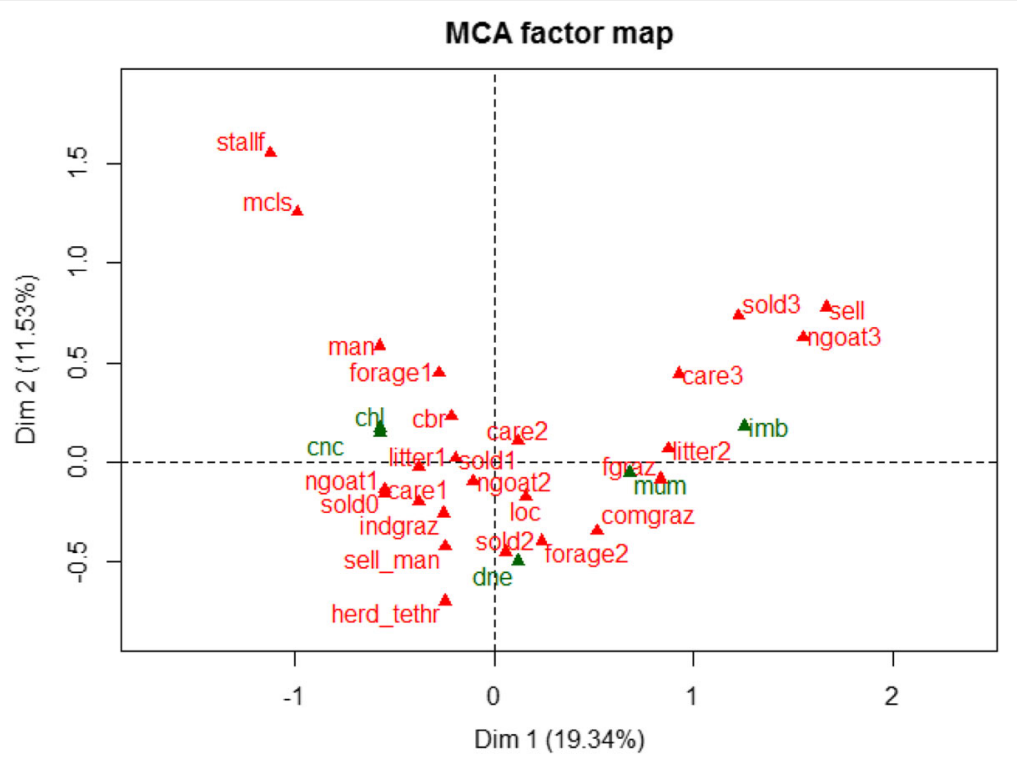

Fig. 2 Result of the multiple correspondence analysis: graphical representation of modalities for the first (Dim1) and second (Dim 2) dimensions. care1, low spending in veterinary care; care2, medium spending in veterinary care; care3, high spending in veterinary care; cbr, mixed flock with indigenous and crossbreds; chl, central highlands; cnc, Congo-Nil-Crest; comgraz, communal grazing; dne, Depressions of the Northeast; fgraz, free grazing; forage1, use of forage crops; forage2, no use of forage crops; herd_teth, herding/tethering; imb, Imbo; indgraz, individual pastures; litter1, presence of litter; litter2, absence of litter; loc, local flock; man, manure; mcls, mixed crop-livestock system; ngoat1, small herds; ngoat2, medium herds; ngoat3, large herds; sell, sale of goats; sell_man, sale of goats and manure; sold0, no sales of goats; sold1, low income from sales; sold2, medium income from sales; sold3, high income from goats sold. Green colour indicates the illustrative variable of agro-climatic zone

according to the second and third dimensions $(8.89 \%$ of the total variance). The third dimension discriminated herds in which goats are kept under the herding/tethering mode with individual pastures (positive values) from those in which goats are kept under the free-grazing mode with communal pastures (negative values).

Results of the hierarchical classification analysis led us to define three clusters of farmers. Their distribution according to the first two dimensions identified in the MCA is given in Fig. 4. All variables contributed significantly to the construction of the clusters (Table 2).

The first cluster (62 respondents) included farmers with small herds composed of local and crossbred goats kept in MCLS, mainly targeting manure production (both negative and positive values of the first and second MCA dimensions). A scrutiny of the percentages (Table 2) reveals that goats in these herds were mostly stall-fed with forage crops. About $61.3 \%$ of these 62 respondents had small (53.2\%) to medium (43.6\%) herds composed of indigenous and crossbred goats. They firstly kept goats either for manure (41.9\%) or for sale (53.3\%). Almost all of these farmers (93.5\%) used litter to enhance the production of manure. Moreover, they spent little money on veterinary drugs (74.2\%). Income from the sale of goats was low (29\%), and $45.2 \%$ of the farmers did not sell any animals. The majority of these farmers were in the CHL (63\%) and CCN (30.6\%) zones.
The second cluster (194 respondents) included farmers of small herds composed of indigenous breed goats kept in herding/tethering mode, with less market characteristics. In this cluster, the predominant grazing mode was herding/tethering (56.4\%), either on communal (58.8\%) or on individual pastures (41.2\%). The herd size was medium (52.5\%) or small (42.2\%). Around two thirds of the respondents (61.3\%) kept only pure indigenous goats. Income from the sale was either low (23.2\%) or medium (23.2\%), and $43.6 \%$ of the farmers did not sell their goats. The majority of the respondents in this cluster (76.5\%) firstly kept goats to produce manure and to sell the animals later. They were mostly farmers of the CHL (33.5\%), DNE (26\%) and CNC (18.6\%) zones.

The last cluster (63 individuals) included farmers of large herds composed of indigenous breed goats (75.1\%) which graze freely in communal pastures (81.1\%). Around $70 \%$ of them did not use forage crops to feed their goats. Herd size was greater than 10 heads (75.5\%). Among the 63 respondents, $86.8 \%$ primarily kept goats for sale and the level of income from these sales was high for $71.7 \%$ of them. This cluster was dominated by farmers located in the IMB (39.6\%), MUM (37.7\%) and DNE (19\%) zones.

The main purchasers of goats sold by the respondents were significantly different among clusters. Breeders of cluster 1 sold their goats mostly to intermediaries whereas those of cluster 3 sold them to butchers or 


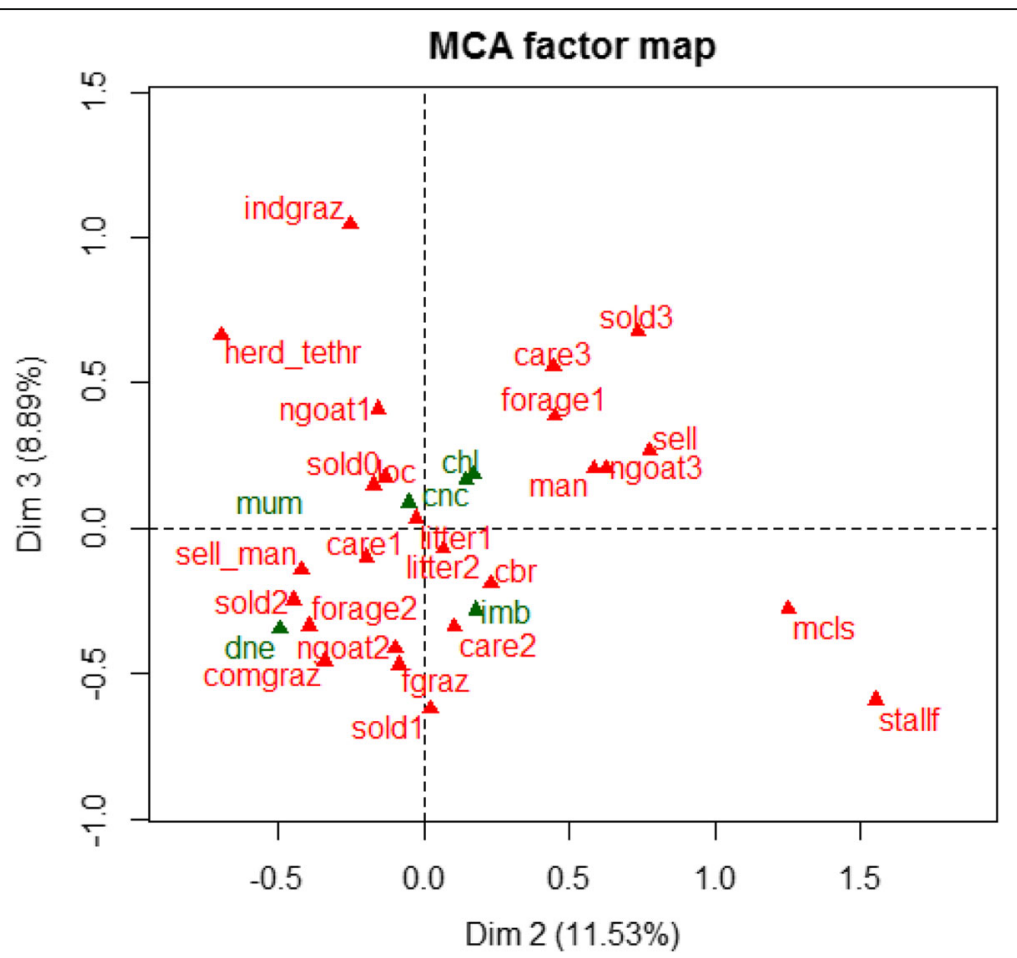

Fig. 3 Result of the multiple correspondence analysis of the answers to a survey of goat keepers in Burundi: graphical representation of modalities for the second (Dim 2) and third (Dim 3) dimensions. See signification of codes in Fig 2

directly to the market. The time to reach the goat marketplace was significantly shorter in cluster 3 than in the others.

\section{Animal characteristics}

Least squares means (LSM) are given in Table 3. The LSM ( $\pm=$ standard error) for BW, CG, BL and HW of crossbreds were $4.74 \pm 0.93 \mathrm{~kg}, 4.78 \pm 0.49 \mathrm{~cm}, 5.59 \pm$
$0.55 \mathrm{~cm}$ and $4.82 \pm 0.4 \mathrm{~cm}$ higher than those of the local breeds, respectively. The LSM for BW, CG, BL and HW of goats more than 3 years old were respectively $14.58 \pm 3.08 \mathrm{~kg}, 12.4 \pm 0.86 \mathrm{~cm}, 9.41 \pm 0.94 \mathrm{~cm}$ and $7.84 \pm 0.79 \mathrm{~cm}$ higher than those from goats of lesser age. No significant difference was found in BW and linear measures between grazing modes. Males were slightly heavier than females with a non-significant

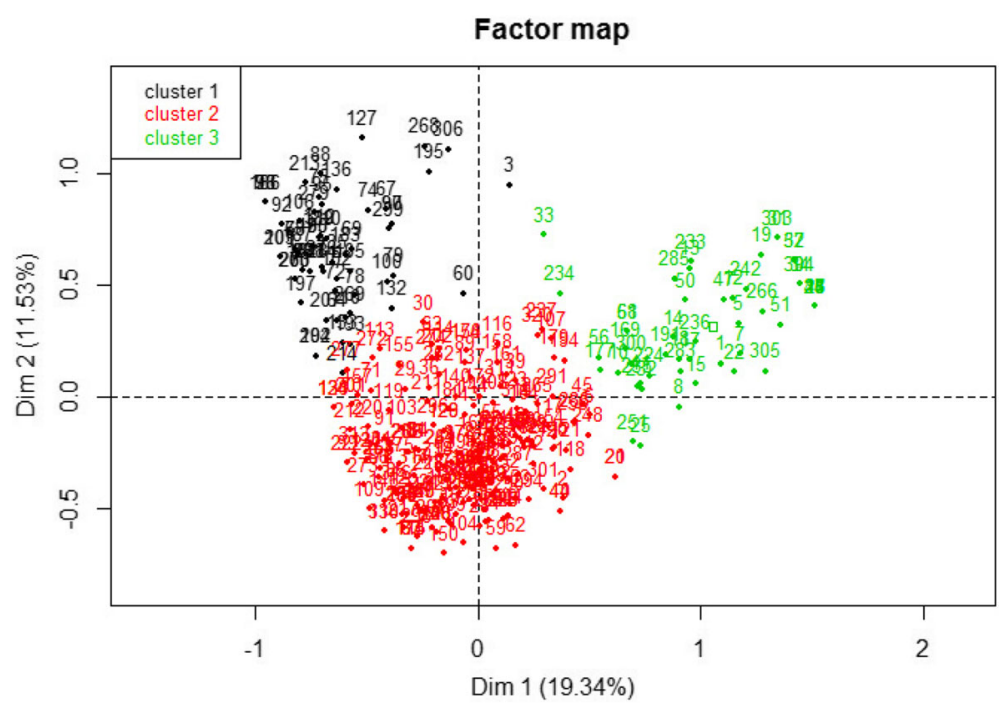

Fig. 4 Graphic representation of the three clusters (numbers correspond to individuals interviewed) on the first two dimensions 
Table 2 Percentage of responders per categories for the three clusters identified by the hierarchical classification analysis

\begin{tabular}{|c|c|c|c|c|c|}
\hline Variables and categories & Cluster 1 & Cluster 2 & Cluster 3 & Total & Stat $^{a}$ \\
\hline Grazing mode & & & & & *** \\
\hline Free grazing & 0 & 37.7 & 88.7 & 38.9 & \\
\hline Herding/tethering & 0 & 56.4 & 9.4 & 37.6 & \\
\hline Mixed crop-livestock system & 100 & 5.9 & 1.9 & 23.5 & \\
\hline Pasture area & & & & & $* * *$ \\
\hline Individual grazing & 12.9 & 41.2 & 18.9 & 31.9 & \\
\hline Communal grazing & 1.6 & 58.8 & 81.1 & 51.4 & \\
\hline Stall feeding & 85.5 & 0 & 0 & 16.6 & \\
\hline Type of flock & & & & & * \\
\hline Flock with only pure indigenous goats & 38.7 & 61.3 & 65.1 & 57.1 & \\
\hline Flock with indigenous goats and Boer crossbreds & 61.3 & 38.7 & 34.9 & 42.9 & \\
\hline Use of forage crops in the feed & & & & & $* *$ \\
\hline Yes & 72.6 & 41.2 & 39.7 & 46.7 & \\
\hline No & 27.4 & 58.8 & 60.3 & 53.3 & \\
\hline Presence of litter in the stall & & & & & *** \\
\hline Yes & 93.5 & 76.3 & 28.3 & 69.9 & \\
\hline No & 6.5 & 23.7 & 71.7 & 30.1 & \\
\hline First purpose for keeping goats & & & & & $* * *$ \\
\hline Manure & 41.9 & 21.5 & 1.9 & 22.2 & \\
\hline Sale & 4.8 & 2 & 86.8 & 16.6 & \\
\hline Both (manure and sale) & 53.3 & 76.5 & 11.3 & 61.2 & \\
\hline Size of the herds & & & & & $* * *$ \\
\hline Small: less than 5 heads & 53.2 & 42.2 & 3.8 & 37.9 & \\
\hline Medium: 5 to 10 heads & 43.6 & 52.3 & 20.7 & 45.5 & \\
\hline Large: over 10 heads & 3.2 & 5.5 & 75.5 & 16.6 & \\
\hline Level of income from goats' sale (in the year following the survey) & & & & & $* * *$ \\
\hline No sales of goats & 45.2 & 44.8 & 1.9 & 37 & \\
\hline Low: less than $50,000 \mathrm{BIF}$ & 29.0 & 23.2 & 9.4 & 22.6 & \\
\hline Medium: from 50,000 to $100,000 \mathrm{BIF}$ & 14.5 & 23.2 & 17 & 21.3 & \\
\hline High: more than $100,000 \mathrm{BIF}$ & 11.3 & 8.8 & 71.7 & 19.1 & \\
\hline Money spent for veterinary care (in the year following the survey) & & & & & $* * *$ \\
\hline Low: less than $5000 \mathrm{BIF}$ & 74.2 & 65.7 & 20.7 & 59.9 & \\
\hline Medium: from 5000 to $10,000 \mathrm{BIF}$ & 14.5 & 18.6 & 18.9 & 17.8 & \\
\hline High: more than $10,000 \mathrm{BIF}$ & 11.3 & 15.7 & 60.4 & 22.3 & \\
\hline Agro-ecological zone & & & & & $* * *$ \\
\hline Central highlands & 63 & 33.5 & 1.9 & 33.8 & \\
\hline Congo-Nil-Crest & 30.6 & 18.6 & 1.8 & 17.6 & \\
\hline Depressions of the Northeast & 0 & 26.3 & 19 & 19.7 & \\
\hline Mumirwa & 3.2 & 13.9 & 37.7 & 15.9 & \\
\hline Imbo & 3.2 & 7.7 & 39.6 & 12.9 & \\
\hline
\end{tabular}

${ }^{*} p^{<} 0.05 ;{ }^{* *} p<0.01 ; * * * p^{<} 0.001$

${ }^{a}$ Statistical significance of the chi-square or exact Fisher's test for differences between clusters 
difference of $2.41 \pm 3.16 \mathrm{~kg}$. The LSM of CG and HW for males were respectively $3.15 \pm 0.75 \mathrm{~cm}$ and $3.83 \pm$ $0.7 \mathrm{~cm}$ higher than those of females. We found also a difference between some AEZ: The BW of goats raised in DNE, MUM and IMB were $6.98 \pm 2.46 \mathrm{~kg}$, $4.53 \pm 1.66 \mathrm{~kg}$ and $4.51 \pm 0.58 \mathrm{~kg}$ heavier than those raised in $\mathrm{CNC}$, respectively. The CG for goats raised in IMB and MUM zones were respectively $3.57 \pm 0.82$ $\mathrm{cm}$ and $1.82 \pm 0.86 \mathrm{~cm}$ higher than those raised in $\mathrm{CNC}$ while those for goats raised in $\mathrm{CNC}, \mathrm{CHL}$ and DNE were similar. BW and linear measurements for goats raised in $\mathrm{CNC}$ and $\mathrm{CHL}$ zones were similar.

\section{Discussion}

The main goal of this study was to characterize smallholders' goat production systems and the impact of Boer crossbreeding on goats' body measurements in the process of providing information for implementing a genetic selection programme in these herds.

\section{Descriptive characteristics of herds and animals}

After analyzing the answers to the survey questionnaire, the first finding was that almost no reproductive bucks were present in the herds. Indeed, they were sold too early (5.9 months on average), before the reproductive age, as it has been also reported in other studies of smallholders' goat production systems (Monau et al. 2017; Manzi et al. 2013; Kosgey et al. 2008). Due to the huge consideration of goats as a source of immediate and regular cash $(74.1 \%$ of the respondents), kids with a high growth rate are often sold earlier. Tadesse et al. (2015) also underlined this observation. It could lead to

Table 3 Least-square means (LSM) and standard errors (SE) of body measurements per age group and sex, per genetic group and flock type, and per grazing mode and agro-ecological zone

\begin{tabular}{|c|c|c|c|c|c|}
\hline & & BW (kg) (SE) & CG (cm) (SE) & $\mathrm{BL}(\mathrm{cm})(\mathrm{SE})$ & $\mathrm{HW}(\mathrm{cm})(\mathrm{SE})$ \\
\hline Sex & Age group & & & & \\
\hline \multirow[t]{4}{*}{ Female } & 1 to 2 years & $20.07(0.61)$ & $62.5(0.36)$ & $56.1(0.39)$ & $51.4(0.34)$ \\
\hline & 2 to 3 years & $23.75(0.61)$ & $67.1(0.29)$ & $58.8(0.32)$ & $54.0(0.27)$ \\
\hline & 3 to 4 years & $25.74(0.63)$ & $70.0(0.33)$ & $61.3(0.36)$ & $56.4(0.31)$ \\
\hline & Over 4 years & $27.46(0.63)$ & $72.2(0.36)$ & $63.9(0.39)$ & $57.9(0.34)$ \\
\hline \multirow[t]{4}{*}{ Male } & 1 to 2 years & $20.43(0.79)$ & $68.0(0.74)$ & $59.2(0.83)$ & $57.5(0.70)$ \\
\hline & 2 to 3 years & $23.39(2.41)$ & $75.9(1.41)$ & $67.5(1.56)$ & $63.0(1.33)$ \\
\hline & 3 to years & $26.68(1.25)$ & $73.2(2.82)$ & $63.5(3.13)$ & $61.7(2.65)$ \\
\hline & Over 4 years & $28.93(1.61)$ & $82.0(1.99)$ & $72.9(2.21)$ & $65.8(1.87)$ \\
\hline Type of flock & Type of breed & & & & \\
\hline Local flock & Local & $22.06(0.75)$ & $67.2(0.24)$ & $59.0(0.24)$ & $54.3(0.20)$ \\
\hline \multirow[t]{2}{*}{ Mixed flock } & Boer crossbreds & $27.73(1.21)$ & $71.9(0.41)$ & $64.2(0.41)$ & $59.0(0.35)$ \\
\hline & Local & $23.89(1.29)$ & $67.1(0.46)$ & $58.9(0.47)$ & $53.9(0.39)$ \\
\hline Agro-ecological zone & Grazing mode & & & & \\
\hline \multirow[t]{3}{*}{ Congo-Nil-Crest } & Mixed crops livestock system & $23.12(0.83)$ & $67.8(0.92)$ & $59.3(0.94)$ & $53.7(0.80)$ \\
\hline & Herding & $22.65(1.26)$ & $65.1(0.86)$ & $57.4(0.87)$ & $52.5(0.75)$ \\
\hline & Herding/tethering & $23.32(1.02)$ & $67.9(0.99)$ & $58.0(1.0)$ & $53.9(0.86)$ \\
\hline \multirow[t]{3}{*}{ Central highlands } & Mixed crops livestock system & $23.83(0.55)$ & $68.0(0.62)$ & $60.1(0.63)$ & $54.8(0.54)$ \\
\hline & Herding & $23.03(0.91)$ & $66.7(0.81)$ & $58.5(0.82)$ & $53.2(0.71)$ \\
\hline & Herding/tethering & $23.09(0.92)$ & $66.3(0.55)$ & $58.6(0.56)$ & $53.7(0.47)$ \\
\hline \multirow[t]{3}{*}{ Depressions of the Northeast } & Mixed crops livestock system & $26.51(1.32)$ & $72.4(1.95)$ & $63.6(1.98)$ & $59.6(1.69)$ \\
\hline & Herding & $24.08(0.55)$ & $67.6(0.49)$ & $59.5(0.5)$ & $55.4(0.43)$ \\
\hline & Herding/tethering & $25.49(1.06)$ & $66.5(0.77)$ & $58.4(0.78)$ & $54.7(0.67)$ \\
\hline \multirow[t]{2}{*}{ Imbo } & Herding & $27.47(0.87)$ & $70.8(0.45)$ & $62.1(0.46)$ & $57.3(0.39)$ \\
\hline & Herding/tethering & $27.62(1.57)$ & $69.5(1.62)$ & $62.3(1.65)$ & $56.2(1.41)$ \\
\hline \multirow[t]{3}{*}{ Mumirwa } & Mixed crops livestock system & $23.02(0.83)$ & $70.1(1.42)$ & $63.7(1.44)$ & $57.8(1.23)$ \\
\hline & Herding & $25.86(0.72)$ & $69.4(0.57)$ & $61.5(0.58)$ & $56.5(0.49)$ \\
\hline & Herding/tethering & $24.75(0.97)$ & $67.6(0.79)$ & $60.0(0.80)$ & $54.7(0.68)$ \\
\hline
\end{tabular}


the so-called negative selection by excluding the best bucks from reproduction. Furthermore, it could result in an increase of the inbreeding level in these herds because only a small number of bucks are exchanged among farmers, and this increases the likelihood of close relative mating (Monau et al. 2017). The absence of reproductive bucks and the negative selection highlight the necessity of a genetic management programme. However, the low literacy level of the farmers and the small size of their herds are issues that could impede such a programme. Indeed, recording animal performances and pedigree, both the basics of genetic evaluation, is logistically more feasible in large herds and with trained farmers (FAO 2016; Kosgey et al. 2008).

The second finding was that more than half of the farmers prefer larger crossbred than smaller indigenous goats. Note, however, crossbreeding is only appropriate when animals are housed and fed appropriately so they may express their genetic potential (Zonabend et al. 2017). Whereas Boer crossbreds are advantageous in body size, indigenous animals are more disease resistant as was previously reported (Tindano et al. 2017). This suggests that the best larger indigenous animals, which are more adapted to the prevailing conditions, would be selected as parents of new generations.

\section{Typology of goat production systems}

The third finding was the observation that breeding objectives and practices are different across groups of farmers, as shown by the results of the multivariate analyses. These results reveal two opposite groups and one intermediate group from the perspective of AEZ, grazing management, herd size, and market characteristics.

One group was more interested in producing manure than in the goats themselves. Herds are small, and farmers tend progressively to keep their animals in the enclosure (MCLS) and to raise Boer crossbreds. This group is located in humid highland $\mathrm{CHL}$ and $\mathrm{CNC}$ zones where manure is crucial for renewing the soil fertility of the doubled-cropped fields (Cochet 2004). An explanation for these findings is linked to the high human population pressure in those zones, which may lead to low availability of grazing areas as was reported by Kosgey and Okeyo (2007). These authors highlighted that MCLS is mainly found in areas with medium to high agricultural potential. In Rwanda, with a high human population density like in Burundi, free grazing practices tend to be replaced by zero grazing (Manzi et al. 2013). Apart from the advantages of producing high quantities of manure, the trend to practice MCLS may also enable a mating control for genetic improvement. Nonetheless, the greater interest of these farmers to produce manure than to sell goats, as well as the low flock size, could hinder its sustainability. Indeed, many authors have reported that the sustainability of breeding programmes for local breeds of small ruminants in low-input production systems depends on farmers' interest, resulting from the socio-economic context of production (Biscarini et al. 2015; Kosgey et al. 2006).

Another group of farmers was more interested in selling their animals. This group is located in the lowlands of IMB, MUM and DNE where herds tend to be large (over 10 goats) and animals to graze freely in communal pastures. These results corroborate with those of Kosgey and Okeyo (2007) who concluded that large indigenous herds are predominant in areas with low agriculture potential. This may be attributed to the long dry season ( 5 to 6 months) which limits forage crop production required for MCLS adoption.

This group of farmers is likely to respond favourably to the establishment of a genetic programme, especially since they tend to be more market-oriented than the first group. Indeed, they sell their animals directly to butchers and markets and not to intermediaries, which shows that these zones are more goat meat consumers compared to humid highland zones. These high market characteristics were underlined as the main drivers of a breeding programme (Gobena and Tona 2017; Tadesse et al. 2015). However, animals are often left without any supervision during the day in these communal pastures, making the mating control more difficult, as underlined by Tindano et al. (2017).

\section{Animal characteristics}

The fourth finding was that mean BW of Boer crossbreds were higher than mean BW of indigenous goats, as reported elsewhere (Deribe et al. 2015; Kalenga et al. 2015), but smaller than the $28.7 \mathrm{~kg}$ theoretically expected in the absence of heterosis. This theoretical value was obtained by averaging the weight of our indigenous goats $(22.3 \pm$ $4.1 \mathrm{~kg}$ ) and the weight of pure Boer goats raised under extensive humid tropical conditions $(35.1 \pm 1.32 \mathrm{~kg})$ as reported by Nguluma et al. (2013). Similarly, a small BW increase was reported for crossbred goats in Ethiopia (Deribe et al. 2015): they stated that birth and weaning weights of Boer crossbreds were significantly higher than weights of local breeds, but the difference dwindled as the age of kids advanced. These observations may be explained by the management conditions not allowing animals to express their genetic potential (e.g. shortage of forage and lack of concentrates, high disease pressure and low veterinary care, associated with a high mortality rate of crossbred's kids). These findings corroborate with those of other researchers (Ayalew et al. 2003; Kosgey et al. 2006; Leloy et al. 2016; Manirakiza et al. 2017). They highlighted that crossbreeding programmes do not always meet expectations in developing countries due to the low adaptability of crossbreds to low-input traditional production systems. This caused the recommendation of 
improvement programmes to be based on selective breeding within indigenous populations to produce animals well adapted and rationally productive in their harsh environments (Mirkena et al. 2012; Mueller et al. 2015). It is also important to note that the income from the sale of goats was significantly lower in mixed flocks of small size (cluster 1) than in large flocks with indigenous animals (cluster 3). This suggests, as observed by Ayalew et al. (2003), that higher individual body weights and sizes are not the only key elements to generate the highest benefits, as a large flock could be also important.

Considering the other effects included in the fixed models, we would mention the lower weights and linear measures for goats raised in highlands (CHL and $\mathrm{CNC}$ ) than in lowlands (DNE, IMB, MUM). An explanation for this may be that coldness and high relative humidity in highlands may affect production performances and compromise the immune system, which makes the animals prone to diseases (Melissa et al. 2017; Rashamol et al. 2018). The last observation in this section is that mean weight $(22.3 \mathrm{~kg}$ ) of indigenous goats was within the range expected for Small Eastern African goats of 20 to $30 \mathrm{~kg}$ in Kenya (Mbuku et al. 2015).

\section{Conclusions and recommendations}

Goats' breeding in Burundi seems better developed in dry lowlands where herds are large, mainly composed of indigenous breeds and managed in an extensive system as free grazing mode, in contrast to the humid highlands where herds are small, mixed with crossbreds and managed either in stall-feeding or in herding/tethering mode. Furthermore, farmers of lowlands had higher market characteristics compared to those of humid highlands who firstly focused on manure production more than the sale of goats. Boer crossbreds outperform indigenous breeds but not to the level expected from the performances of the pure breeds. Policies aiming at managing goat genetic resources in Burundi should focus on bucks' management through selection within indigenous breeds, as an alternative to the importation of Boer bucks.

\footnotetext{
Abbreviations

AEZ: Agro-ecological zone; BIF: Burundian franc; BL: Body length; BW: Body weight; cbr: Mixed herd with indigenous and crossbreds; CG: Chest girth; CHL: Central highlands; CNC: Congo-Nil-Crest; comgraz: Communal grazing; DNE: Depressions of the Northeast; FAO: Food Agriculture Organization; GLM: General linear model; herd: Herding; herd_teth: Herding/tethering; HW: Height at withers; IMB: Imbo; indgraz: Individual pastures; loc: Local herd; LSM: Least square mean; man: Manure; MCA: Multiple correspondence analysis; MCLS: Mixed crop-livestock system; MIENAGRIE: Ministère de l'Environnement, de l'Agriculture et de l'Elévage; MUM: Mumirwa; SE: Standard error; SEA: Small Eastern African; sell: Sale of goats; sell_man: Sale of goats and manure; TES: Traditional extensive system
}

\section{Acknowledgements}

Authors acknowledge the Food Agriculture Organization (FAO) and ARESResearch and Higher Education Academy of Wallonie and Brussels for financial support. The authors thank the enumerators and farmers who participated in the data collection.

\section{Authors' contributions}

$\mathrm{JM}, \mathrm{GH}$ and BB participated in the design of the study. JM collected and performed the statistical analysis and drafted the manuscript. JD performed the statistical analysis and corrected the manuscript. GH corrected the manuscript. All authors read and approved the final manuscript.

\section{Funding}

FAO financed the data collection. ARES financed the data analysis and interpretation of data.

\section{Availability of data and materials}

Please contact the corresponding author for data requests.

Ethics approval and consent to participate

Not applicable.

Consent for publication

Not applicable.

\section{Competing interests}

The authors declare that they have no competing interests.

\section{Author details}

${ }^{1}$ Department of Animal Health and Productions, Faculty of Agriculture and Bio-Engineering, University of Burundi, BP 2940 Bujumbura, Burundi. ${ }^{2}$ Animal Production and Health Division, FAO, Viale delle Terme di Caracalla, 00153 Rome, Italy. ${ }^{3}$ FARAH, Productions animales durables, Université de Liège, 4000 Liège, Belgium.

Received: 17 May 2019 Accepted: 12 December 2019

Published online: 03 February 2020

\section{References}

Ayalew, W., B. Rischkowsky, and J.M. King. 2003. Crossbreds did not generate more net benefits than indigenous goats in Ethiopian smallholdings. Agricultural Systems 76: 1137-1156. https://doi.org/10.1016/S0308521X(02)00033-1.

Bidou, J.E., S. Ndayirukiye, J.P. Ndayishimiye, and P. Sirven. 1991. Géographie du Burundi, 251. Paris: Hatier.

Biscarini, F., E. Nicolazzi, S. Alessandra, P. Boettcher, and G. Gandini. 2015. Challenges and opportunities in genetic improvement of local livestock breeds. Frontiers in Genetics 6: 33-39. https://doi.org/10.3389/fgene.2015.00033.

Campbell, Q.P. 2003. The origin and description of southern Africa's indigenous goats. South African Journal of Animal Science 4: 18-22.

Cochet, H. 2004. Agrarian dynamics, population growth and resource management: The case of Burundi. GeoJournal 60 (2): 111-122.

Darcan, N.K., and N. Silanikove. 2018. The advantages of goats for future adaptation to climate change: A conceptual overview. Small Ruminant Research 163: 34-38.

Deribe, B., M. Tilahun, M. Lakew, N. Belayneh, A. Zegeye, M. Walle, D. Ayichew, S.T Ali, and S. Abriham. 2015. On station growth performance of crossbred goats (Boer X central highland) at Sirinka, Ethiopia. Asian Journal of Animal Science 9: 454-459. https://doi.org/10.3923/ajas.2015.454.459.

Devendra, C. 2010. Concluding synthesis and the future for sustainable goat production. Small Ruminant Research 89: 126-131. https://doi.org/10.1016/j. smallrumres.2009.12.034.

Erasmus, J.A. 2000. Adaptation to various environments and resistance to disease of the Improved Boer goat. Small Ruminant Research 36: 179-187.

FAO. 2012. Phenotypic characterization of animal genetic resources, 11. Rome: FAO Animal Production and Health Guidelines.

FAO. 2016. Development of integrated multipurpose animal recording systems, 19 Rome: FAO Animal Production and Health Guidelines.

Gobena, M.M., and M.G. Tona. 2017. Sheep production system, marketing and constraints in Ethiopia. Journal of Biology, Agriculture and Healthcare 7 (19): 34-42.

Husson, F., J. Josse, and J. Pagès. 2010. Analyse de données avec $R$ Complémentarité des méthodes d'analyse factorielle et de classification, 1-6. Marseille: 42ème Journée de Statistique. 
Jeníček, V., and S. Grofová. 2015. Least developed countries - the case of Burundi. Agricultural Economics 61 (5): 234-247.

Kalenga, H.K., S. Vandenput, N. Antoine-Moussiaux, N. Moula, J.C.K. Kashala, F. Farnir, and P. Leroy. 2015. Amélioration génétique caprine à Lubumbashi (RDC): 3 . Analyse de la croissance de chevreaux hybrides F1Boer $x$ race locale. Livestock Research for Rural Development 27: 12 http://www.Irrd.org/ Irrd27/12/kale27239.html. Accessed 22 Apr 2019.

Kosgey, I.S., R.L. Baker, H.M.J. Udo, and J.A.M. Van Arendonk. 2006. Successes and failures of small ruminant breeding programs in the tropics: A review. Small Ruminant Research 61: 13-28. https://doi.org/10.1016/j.smallrumres.2005.01.003.

Kosgey, I.S., and A.M. Okeyo. 2007. Genetic improvement of small ruminants in low-input smallholder production systems: Technical and infrastructural issues. Small Ruminant Research 70: 76-88. https://doi.org/10.1016/j. smallrumres.2007.01.007.

Kosgey, I.S., G.J. Rowlands, J.A.M. Van Arendonk, and R.L. Baker. 2008. Small ruminant production in smallholder and pastoral/extensive farming systems in Kenya. Small Ruminant Research 77: 11-24. https://doi.org/10.1016/j. smallrumres.2008.02.005.

Lê, S., J. Josse, and F. Husson. 2008. FactoMineR: An R package for multivariate analysis. Journal Statistical Software 25: 1-18. https://doi.org/10.1016/j.envint. 2008.06.007.

Leloy, G., R. Baumung, P. Boettcher, and I. Hoffmann. 2016. Review: Sustainability of crossbreeding in developing countries; definitely not like crossing a meadow. Animal 10: 262-273. https://doi.org/10.1017/S175173111500213X.

Malan, S.W. 2000. The improved Boer goat. Small Ruminant Research 36: 165-170.

Manirakiza, J., G. Hatungumukama, S. Thévenon, M. Gautier, B. Besbes, L. Flori, and J. Detilleux. 2017. Effect of genetic European taurine ancestry on milk yield of Ankole-Holstein crossbred dairy cattle in mixed smallholders system of Burundi highlands. Animal Genetic 48: 544-550. https://doi.org/10.1111/age.12578.

Manzi, M., J. Mutabazi, C.D. Hirwa, and D.R. Kugonza. 2013. Socio-economic assessment of indigenous goat production system in rural areas of Bugesera District in Rwanda. Livestock Research for Rural Development 25: 11 http:// www.lrrd.org//rrd25/11/manz25205.htm Accessed 23 Apr 2019.

Mbuku, S.M., A.M. Okeyo, I.S. Kosgey, and A.K. Kahi. 2015. Optimum crossbreeding systems for goats in low-input livestock production system in Kenya. Small Ruminant Research 123: 55-61. https://doi.org/10.1016/j.smallrumres.2014.10.001.

Melissa, R.D.M., N.A. Pouyan, T. Harrigan, and S.A. Woznicki. 2017. Climate change and livestock: Impacts, adaptation, and mitigation. Climate Risk Management 16: $145-163$

Ministère de l'Environnement, de l'Agriculture et de l'Elevage (MINEAGRIE). 2010. Stratégie Agricole Nationale. Document d'orientation stratégique pour le secteur de l'Elevage au Burundi. Bujumbura: Republique du Burundi.

Ministère de l'Environnement, de l'Agriculture et de l'Elevage (MINEAGRIE). 2017. Enquête nationale agricole. Campagne agricole 2016-2017. Bujumbura: Republique du Burundi.

Ministère de l'Intérieur. 2010. Résultats définitifs du troisième recensement général de la population et de l'habitat de 2008. Bujumbura: Republique du Burundi.

Mirkena, T., G. Duguma, A. William, M. Wurzinger, A. Haille, B. Rischkowsky, A.M. Okeyo, M. Tibbo, and J. Solkner. 2012. Community-based alternative breeding plans for indigenous sheep breeds in four agro-ecological zones of Ethiopia. Journal of Animal Breeding and Genetics 129: 244-253. https://doi.org/10. 1111/j.1439-0388.2011.00970.x.

Monau, P.I., C. Visser, S.J. Nsoso, and E. Van Marle-Köster. 2017. A survey analysis of indigenous goat production in communal farming systems of Botswana. Tropical Animal Health and Production 49: 1265-1271. https://doi.org/10.1007/ s11250-017-1324-6.

Mueller, J.P., B. Rischkowsky, A. Haile, J. Philipsson, O. Mwai, B. Besbes, A. Valle Zárate, M. Tibbo, T. Mirkena, G. Duguma, J. Sölkner, and M. Wurzinger. 2015. Communitybased livestock breeding programs: Essentials and examples. Journal of Animal Breeding and Genetics 132: 155-168. https://doi.org/10.1111/jbg.12136.

Nguluma, A., M.L. Leite-Browning, and J.R. Browning. 2013. Comparison of BoerCross and foundation breeds for meat goat doe fitness in the humid subtropics. Livestock Research for Rural Development 25 (3): 38 http://www. Irrd.org/Irrd25/3/ngul25038.htm Accessed 23 Apr 2019.

Otte, M.J., and P. Chilonda. 2002. Cattle and small ruminant production systems in sub-Saharan Africa. A systematic review. Rome: Food and Agriculture Organization of the United Nations.

Peacock, C. 2005. Goats-A pathway out of poverty. Small Ruminant Research 60: 179-186.
Pragna, P., S.C. Surinder, S. Veerasamy, B.J. Leury, and F.R. Dunshea. 2018. Climate change and goat production: Enteric methane emission and its mitigation. Animals 8: 235. https://doi.org/10.3390/ani8120235.

Rashamol, V.P., V. Sejian, M. Bagath, G. Krishnan, P.R. Archana, and R. Bhatta. 2018. Physiological adaptability of livestock to heat stress: An updated review. Journal of Animal Behavior and Biometeorology 6: 62-71. https://doi.org/10. 26667/2318-1265jabb.v6n2p62-71.

Skapetas, B., and V. Bampidis. 2016. Goat production in the world: present situation and trends. Livestock Research for Rural Development 28: $11 \mathrm{http}: / /$ www.Irrd.org//rrd28/11/skap28200.htm Accessed 30 Sept 2019.

Tadesse, E., T. Negesse, and G. Abebe. 2015. Sheep production and marketing system in southern Ethiopia: The case of Awassazuria district. Tropical Animal Health and Production 47: 1417-1425. https://doi.org/10.1007/s11250-015-0852-1.

Tarawali, S., M. Herrero, K. Descheemaeker, E. Grings, and M. Blümmel. 2011. Pathways for sustainable development of mixed crop livestock systems: Taking a livestock and pro-poor approach. Livestock Science 139: 11-21.

Tindano, K., N. Moula, A. Traoré, P. Leroy, and Antoine-Moussiaux. 2017. Assessing the diversity of preferences of suburban smallholder sheep keepers for breeding rams in Ouagadougou, Burkina Faso. Tropical Animal Health and Production 49: 1187-1193.

Wilson, R.T. 1991. Small ruminant production and the small ruminant genetic resource in tropical Africa. FAO Animal Production and Health Paper 88. Rome: Food and Agriculture Organization of the United Nations.

Zonabend, K.E., E. Strandberg, J.M.K. Ojango, T. Mirkena, A.M. Okeyo, and J. Philipsson. 2017. Pure breeding of Red Maasai and crossbreeding with Dorper sheep in different environments in Kenya. Journal of Animal Breeding and Genetics 134 (6): 531-544.

\section{Publisher's Note}

Springer Nature remains neutral with regard to jurisdictional claims in published maps and institutional affiliations.

\section{Submit your manuscript to a SpringerOpen ${ }^{\circ}$ journal and benefit from:}

- Convenient online submission

- Rigorous peer review

- Open access: articles freely available online

- High visibility within the field

- Retaining the copyright to your article

Submit your next manuscript at $\boldsymbol{\sim}$ springeropen.com 